\title{
Visualizing the molecular machines of bacterial motility in-situ with electron cryotomography
}

\author{
Grant J. Jensen, Gavin E. Murphy, Greg P. Henderson, Zhuo Li, \\ Arash Komeili, Jared R. Leadbetter, and Dianne K. Newman \\ California Institute of Technology
}

Bacterial motility involves a number of molecular machines. Force-generating engines like the flagellar motor propel cells. Chemoreceptor systems guide cells towards favorable locations. Surface structures facilitate penetration through different environments, and internal structures keep cells moving in a generally straight path. In many cases, our knowledge of these machines is limited because they cannot be purified intact. We have recently recorded electron cryotomograms of several different bacterial species where these machines can be visualized in-situ in a complete, near-native (frozenhydrated) state. In some cases, multiple copies of a particular machine can be extracted from the tomogram, aligned in 3-D, and averaged to improve clarity. Several examples will be presented. In the case of the flagellar motor, the stator was seen to have 16 symmetric "studs" which each contact the rotor directly in two places through finger-like densities. The large, multi-jointed, dyamic core of the attachment organelle in Mycoplasma pneumoniae was seen to be a new motor underlying one form of "gliding" motility. The magnetosome chain in Magnetospirillum magneticum was seen to be a series of membane invaginations held in line by an actin-like cytoskeletal filament. These results highlight how cryotomography can reveal the structure and arrangement of individual machines as they work together within complete systems. 


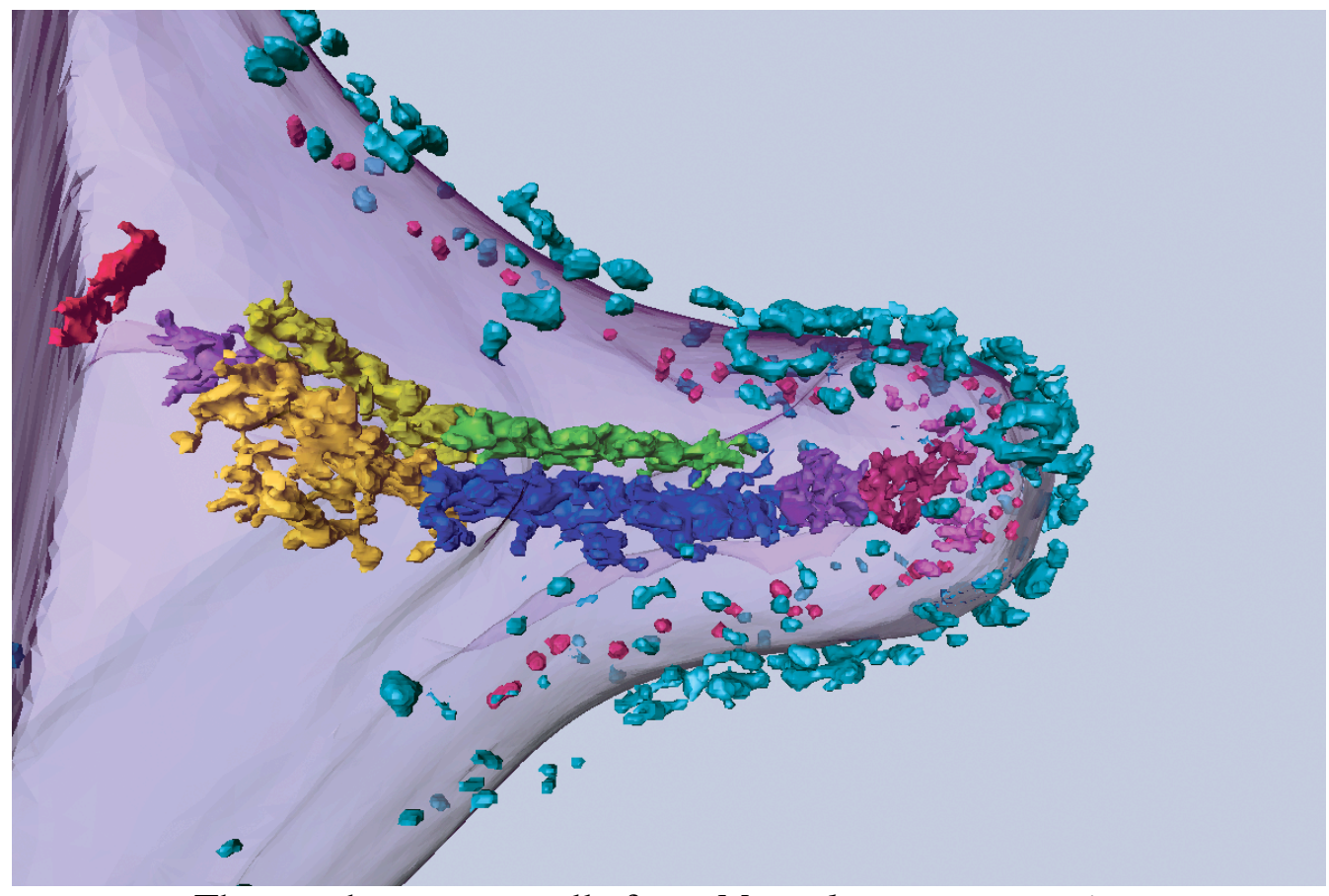

The attachment organelle from Mycoplasma pneumoniae.

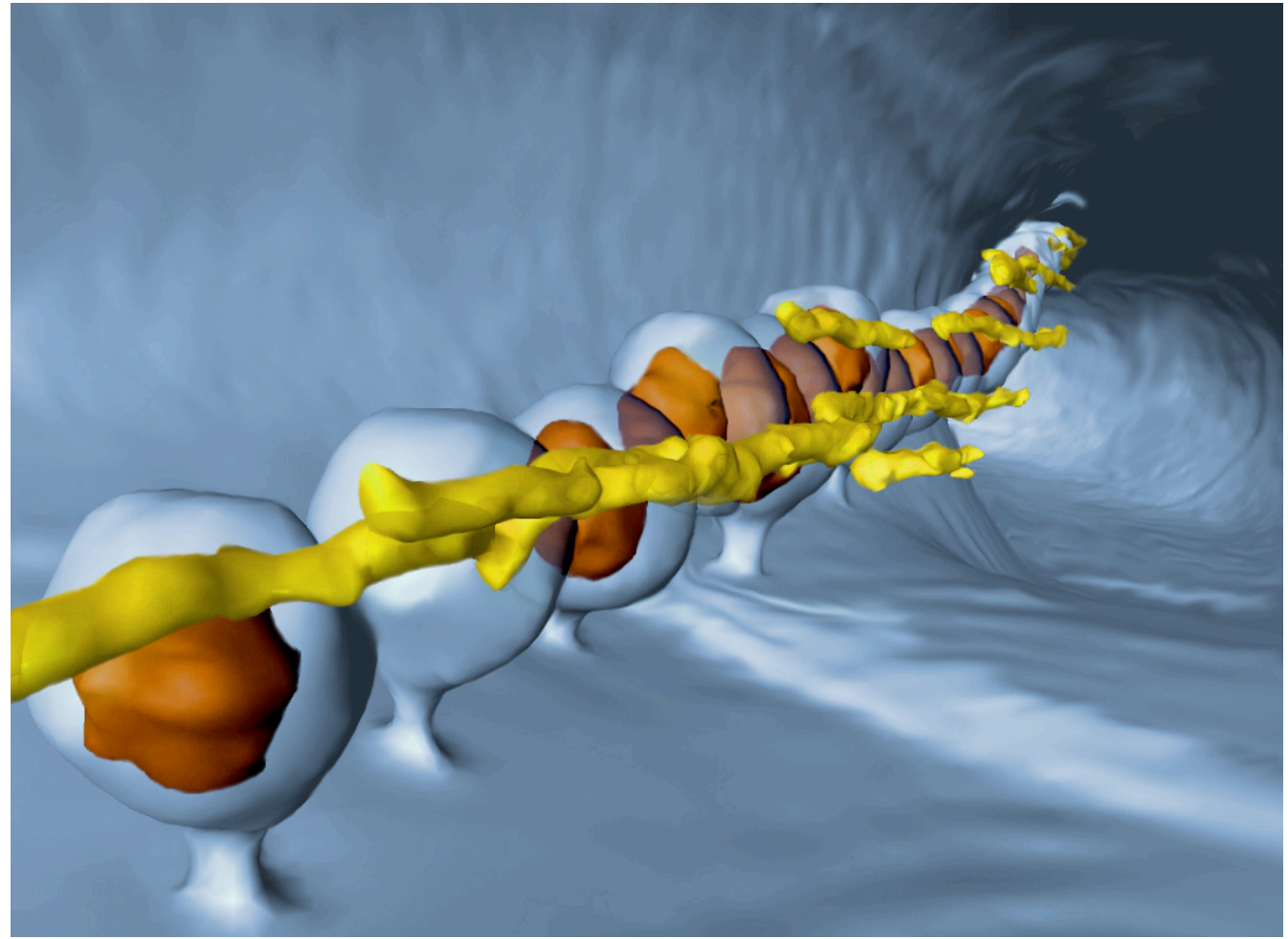

The magnetosome chain in Magnetospirillum magneticum. 